\title{
Bi-Directional Interaction between Systemic Botrytis Cinerea, and Aphid Myzus Persicae on Lettuce Plant
}

\author{
Yahaya $\mathrm{SM}^{*}{ }^{*}$, Ali MU ${ }^{1}$, Lawan $\mathbf{M}^{1}$, Amina $\mathrm{LA}^{2}$, Sadiya $\mathrm{AB}^{2}$, Maimuna $\mathrm{MD}^{2}$, Ibrahim $\mathrm{AM}^{2}$, Musa $\mathrm{MJ}^{2}$ and Tasiu \\ $\mathrm{AM}^{2}$
}

${ }^{1}$ Department of Biology, Kano University of Science and Technology, Nigeria

${ }^{2}$ Department of Biochemistry, Kano University of Science and Technology, Nigeria

Received: August 07, 2017; Published: September 06, 2017

*Corresponding author : Yahaya SM, Department of Biology, Kano University of Science and Technology, Nigeria, Tel: +2348063537647 ;

Email: sanimyahya@gmail.com

\begin{abstract}
Bi-directional interaction between economically important fungal pathogen Botrytis cinerea and aphid Myzus persicea causes serious economic losses to the crop plants resulting in loss of both time and money spend. In bi-direction interaction the fungal pathogen and insect herbivores, can both interact directly with the plant and interact indirectly with each other as they struggle to compete for the resources of the plant. We investigated the bi-directional interaction between the necrotrophic and economically important fungal pathogen Botrytis cinerea Pers Fr (Helotiales Sclerotiniaceae) and the aphid Myzus persicae (Hemiptera Aphididae) on plant host, lettuce Lactuca sativa (Asteraceae: Compositae). Botrytis cinerea on host plant causes a brownish discoloration of the leaf petiole accompanied by the rotting of the leaves, however, presence of aphids on lettuce plants causes' economic damage directly through injury and indirectly through virus transmission, resulting in wilting and head contamination.

In this study, it was found that negative interaction between B. cinerea and Myzus persicae was established. The presence of fungal pathogen B. cinerea and Myzus persicae stressed the host lettuce plant, resulting in significant reduction in the rate of photosynthesis and chlorophyll fluorescence, and reduction in the dry shoot and root weight of the lettuce plant. The study established that aphid population growth rate and the number of $B$. cinerea lesions decreased when both were present on the same host plant.
\end{abstract}

Keywords: B. cinerea; Chlorophyll fluorescence Myzus persicae; Rate of photosynthesis; Systemic infection

\section{Introduction}

The ability pathogenic micro-organism such as viruses, bacteria, fungi and nematodes Agrios 2005, and insect herbivores (e.g. aphids) to transmit diseases both in the field and greenhouses [1] are of potent economic importance Agrios, 2005. Some of these diseases are seed-borne [2], while others are air-borne [3], in addition there are others which are transmitted by insects [4]. These pathogenic micro-organisms and insect pests in plants can have a significant negative impact on the plant and its products because of their ability to spread rapidly, resulting in serious economic losses [5].

Systemic and model necrotrophic fungal pathogen Botrytis cinerea (teleomorph Botryotinia fuckeliana) the causative agent of soft rot disease, is identified as one of the most important pathogens causing serious economic losses of crops and vegetables [6-9] and account for substantial pre- and post-harvest losses of crops and vegetables, especially in temperate regions [10]. It is found to cause greater economic loss on crops, vegetables and other ornamental plants than any other fungal disease Agrios 2005; [11,12]. Symptoms shown by the infected plants vary greatly depending on part of the host plant infected [9].
The general symptoms shown by the infected plants include soft rots, associated with water soaking and browning of tissues, accompanied by the appearance of grey masses of conidia on rotted tissues [9]. The pathogen produces copious clear or grey conidia on long branched conidiophores which may be dispersed by humid air currents, splashing water, tools and clothing; the conidiophores initiate a new infection on healthy plants Agrios 2005 [13]. The conidia may infect plant seedlings, flowers, stems, or leaves through wound senescent tissues and directly through the epidermis of the plant Agrios 2005 [14].

Symptoms may appear very quickly and infection may remain quiescent and appear later when tissues age or during storage $[15,16]$. However, in lettuce plants the fungus causes a characteristic collar rot [17] the infected plants may develop brown necrotic lesions on the stem near the soil surface and on the lower leaves. The infection may gradually spreads upwards; as infection continues the infected plants may wither and die in a short time [18].

Over 4,700 aphid's species are known worldwide out of which; only 450 species all belonging to the family Aphididae were found 
to be of importance to the crop plants [19] Majority of aphid (Hemiptera: Aphididae) species are autoecious they survive on one or a few plant species Eastop, 1972 although, few species such as Myzus persicae are polyphagous, some genotypes from polyphagous species are sequentially monoecious they perform better on some particular plant species [20-22]. According to Blackman and Eastop (2000) this specificity is associated with the behavioural responses, chemical and morphological cues in addition to other evolutionary reasons.

The green peach potato aphid M. persicae is a dynamic, rapidly evolving small soft-bodied [23] (phytophagous plant sucking insects, with a complex life history [24,25]. which has a complicated life cycle involving regular movement between deciduous woody plants (the primary host; at the beginning and end of the season) and the secondary host (herbaceous plants) during the summer [26] In the autumn the winged female lays eggs on the primary host and dies. The eggs hatch in the spring giving rise to wingless females which mature and give rise to several generations of wingless females asexually, by means of parthenogenesis.

In many insect herbivores, the quality of the plant and ambient temperature are the two important environmental factors influencing the life history of aphids [27]. Therefore, the actively growing or senescing plants provide better quality food which however, decline as the plant deteriorates. However, the ability of the aphid to adjust to the changes in the food quality is a great survival strategy [28] Aphids reproduce both sexually and asexually, producing eggs which overwinter but otherwise give birth to the live young [6]. The reproduction, size and survival rate depends on the quality of food available to the aphids where changes in nutritional effects may accumulate over several generation resulting in increase or decrease in body size of the aphids [28].

Lettuce Lactuca sativa L. (Asteraceae (Compositae) is an important horticultural crop, widely used throughout the world as source of cash and food (Norman, 1992; [29] with seed oil shown to have analgesic and sedative properties [29]. The aphids infecting lettuce plants are a problem worldwide causing serious economic losses resulting is shortage of production and high cost of the commodity [30]. Although heavy aphid numbers can stunt plants, the most significant consequences of aphid attack is wilting and head contamination, which make lettuce unmarketable [1]. Many aphid species attack lettuce; the most common aphid pest of lettuce is the green peach-potato aphid (Myzus persicae Sulzer). Other aphids which may occasionally infect lettuce include the potato aphid, (Macrosiphum euphorbiae Thomas), the foxglove aphid, (Aulacorthum solani Kaltenbach) and the buckthorn aphid, (Aphis nasturtii Kaltenbach) [1,24,30].

Aphid which are herbivorous insect and pathogenic fungi interact negatively with each other because of their ability to share resources from the same host plant [31]. The interaction is indirect where the first attacker changes the fitness of the host plant in a way that it affects the second attacker $[32,33]$ the interaction serves as a determinant of the population dynamics of both arthropods and pathogens in controlled and natural ecosystems [33,34]. Hatcher et al. [35] reported that this interaction reveals much about the coordination and integration of the plant defenses against multiple threats. Such interactions may be beneficial, detrimental or neutral due to chemical and or physical factors which may lead to synergistic, additive, equivalent or inhibitory effects on the performance of the plant against the individual effect of each antagonist [32,36]. The success of the interaction is somehow dependent on the types of herbivore and pathogen involved [35,37].

In a previous research of plant-mediated indirect interaction it was shown that aphids and fungal pathogens exhibited a bidirectional detrimental effect on the performance of each other due to differences in their feeding strategies. Therefore the aim of the present study was investigate shed lighter on the indirect interaction between a systemic pathogen and an insect herbivore on host plant. We tested four hypotheses (i) that stress resulting from aphids attaching lettuce plants systemically infected by the pathogen $B$. cinerea would influence the spread and expression of $B$. cinerea in lettuce plants (ii) that fungal pathogens and aphids affects host plant traits (iii) that $B$. cinerea affects the growth of M. persicae on host plant, and (iv) that Myzus persicae affects the growth of $B$. cinerea on the host plant.

\section{Material and Methods}

\section{Experimental plants}

Lettuce seeds Tom Thumb variety was sown in $40,15 \mathrm{~cm}$ diameter pots filled with a vermiculite-based growing medium in a controlled environment room (18-200C, ambient humidity and 12-14 h L: D). Twenty plants were grown from uninfected seeds whilst the remaining twenty plants were grown from systemically infected seeds collected from plants inoculated at the flower stage and tested by plating on plates containing Botrytis selective media (BSM).

\section{Infestation of lettuce plant with aphid Myzus persicae}

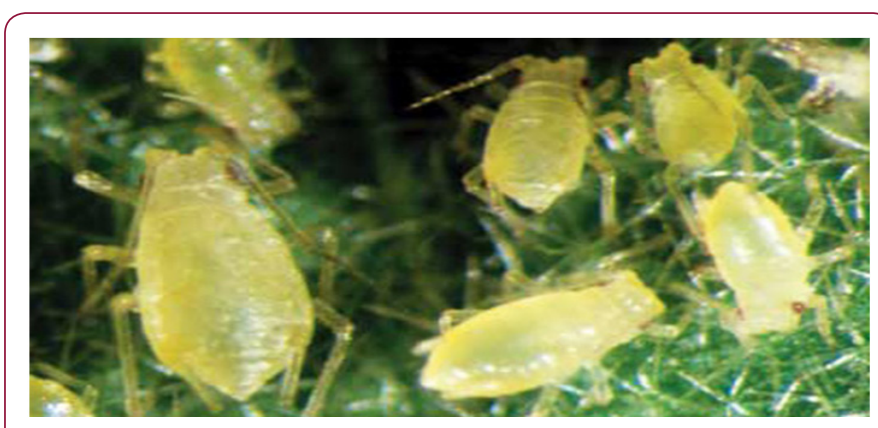

Figure 1: Nymphs of the green peach aphid Myzus persicae (Sulzer).

The aphid species Myzus persicae Sulzer (Hemiptera Aphididae) were reared on lettuce plants for three generations before used in the experiment, allowing for possible effects of telescoping generations (Dixon,1985). Ten plants from each of the two treatments were infested with three aphids. Infestation was achieved by placing the aphids on the reverse side of the leaves using a small moist brush. There after plants were covered with a vented plastic container. The remaining uninfected plants served as controls (Figure 1). 


\section{Size of aphid population}

Aphid population size was assessed by direct count. Counting was done after every three days for eleven weeks, starting one week after infestation. Visual examination was used to assess the appearance of $B$. cinerea infection on the plants (Figure 2).

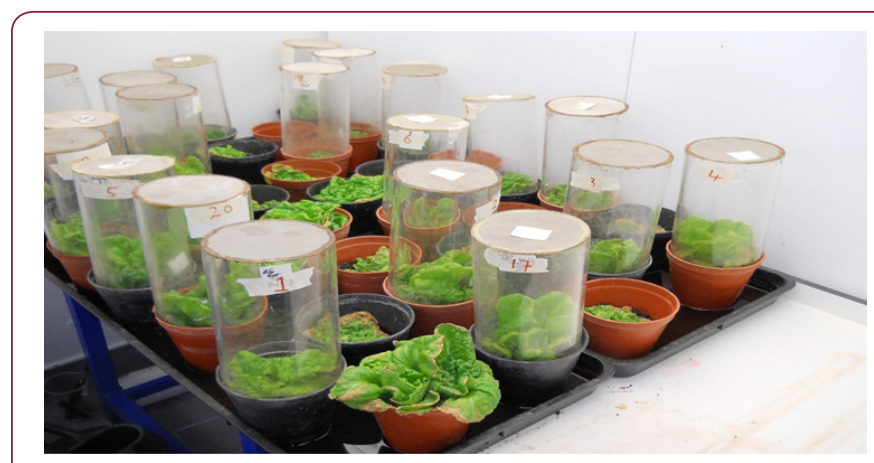

Figure 2: Randomisation test of infested and uninfected plants grown from infected and uninfected lettuce seed

\section{Rate of Photosynthesis}

To determine the level of plant stress induced on the plants the rate of photosynthesis was measured in all the lettuce plant before harvest. The rate of Photosynthesis was measured as the amount of $\mathrm{CO}^{2}$ assimilated per $\mathrm{m}^{2}$ leaf surface by intact leaves, using a Red Gas Analyser (ADC Bioscientific LCi Analyser No. 31109) equipped with standard broadleaf chamber measuring an area of $6.5 \mathrm{~cm}^{2}$. The level of $\mathrm{CO}_{2}$ in the analyzer varied between 400-655mol CO$/$ mol determined by position of the inlet of the analyzer outside the controlled environment. Leaves were allowed 2-4 min in the chamber to reach equilibrium before the readings were recorded.

\section{Rate of Chlorophyll Fluorescence}

The rate of chlorophyll fluorescence was determined as the amount of re-emitted light from the leaf, using a Handy Pea Data Chlorophyll Fluorometer (Hansatech Instrument Ltd. Pea plus version: 1.02). Leaves were placed in the chamber for $20 \mathrm{~min}$ before taking the measurement. The rate of chlorophyll fluorescence was determined as PS11 photochemical efficiency Fv/Fm (where Fv is the maximal variable chlorophyll fluorescence, and Fm is maximal chlorophyll fluorescence).

\section{Measurement of inter node length}

The length of the inter node of all the experimental plants was taken immediately after harvest. The measurement was taken using a ruler.

\section{Measurement of dry shoot weight}

For the determination of dry shoot, harvested shoots were removed from all the 40 plants and washed under running tap water, then dried at room temperature on the laboratory bench. Weight was measured using an electronic balance (Kern scale Technic, 440-21N).

\section{Measurement of dry root weight}

Dry root weight was taken from all the plants. Roots were washed under running tap water and allowed to dry at room temperature on the laboratory bench before taking the measurements using an electronic balance (Kern scale Technic, 440-21N).

\section{Determination of biomass of systemic $B$. cinerea}

Five sets of plants were selected from each of the four treatments and were first washed with distilled water and dried. Plants were sectioned into roots, stems and leaves and disrupted using a pestle and mortar in the presence of liquid nitrogen. Thereafter $100 \mathrm{mg}$ of the resulting fine powder was transferred into an Effendorf tube and DNA was extracted using a DN easy plant mini kit according to the manufacturer's instruction. The volume of DNA was quantified using a nano drop ND-1000 Spectrophotometer (Applied Biosystems). A quantitative polymerase chain reaction (qPCR) was performed with the extracted DNA using scar primers of $B$. cinerea as designed by Suarez et al, (2005) following an established protocol (e.g. $[2,38,39]$ for B. cinerea. A master mix containing $12.5 \mu \mathrm{l}$ qPCR master mix (Qiagen UK), $1 \mu \mathrm{l}$ of each forward and reverse scar primers (Invitrogen), and $5 \mu \mathrm{l}$ of water was prepared and $20 \mu \mathrm{l}$ was aliquoted into each well. To each well $5 \mu$ l of DNA from individual sections of the lettuce plant were added. A standard curve (10ng/ $\mu \mathrm{l}, 1 \mathrm{ng} / \mu \mathrm{l}, 0.1 \mathrm{ng} / \mu \mathrm{l}, 0.01 \mathrm{ng} / \mu \mathrm{l}, 0.001 \mathrm{ng} / \mu \mathrm{l}$, and two water controls) was prepared with the previously quantified DNA extracted from a clean lettuce plant grown from tissue culture propagation. The plates were covered and pulsed in a centrifuge before carrying out the run at 950C for 10 minutes followed by 40 cycles of $600 \mathrm{C}$ for 1 minute, and a 15 second cycle at 950C [40] using a qPCR rotor gene machine (Applied Biosystems).

\section{Experimental design and statistical analysis}

A completely randomised design was used in the experiment. The experimental factors consist of (a) B. cinerea infection status (infected/uninfected),(b) infection with Myzus persicae (infested/ uninfested) and (c) seedling infestation with three or ten Myzus persicae. The data of all the experiments were analysed by ANOVA to understand the relationship between the dependent variables. Contrasts were used to explore and test single degrees of freedom among treatments when a significant effect was found between treatments. All analyses were performed using MINITAB 16 (Rehman 2013).

\section{Results}

\section{Aphid population growth on infected and uninfected plants}

Aphid colonies grow more slowly on infected plants. The plants infested with three aphids survived for a period of eight weeks but aphids live significantly longer on infected plants than in uninfected ( $F 1,19=14.0, P<0.001)$. The effect of aphids infestation significantly affected the rate of chlorophyll fluorescence, photosynthesis and dry mass of lettuce plants.

\section{$B$ cinerea growth on infested and uninfested plants}

Lesions of B. cinerea (Figure 1) were high in uninfected/infested plant (33\%) compared to the infected/ infested plant (17\%). The effect of $B$. cinerea presence has no effects on the rate of chlorophyll fluorescence. However, the presence of $B$. cinerea significantly affects photosynthesis, dry root and shoots weight (Table 1). 
Table 1: Effect of B. cinerea on lettuce plant infested or uninfested with Myzus persicae.

\begin{tabular}{|c|c|c|}
\hline Parameters & Plant treatment & P value \\
\hline \multirow{2}{*}{ Chlorophyll fluorescence } & infested or uninfested & $\mathrm{F}_{1,39}=2.33, \mathrm{P}<0.123$ \\
$\mathrm{~F}_{1,39}=4.52, \mathrm{P}<0.421$ \\
$\mathrm{~F}_{1,39}=1.07, \mathrm{P}<0.540$
\end{tabular}

\section{Effect of both aphids and infection on lettuce traits}

Photosynthesis: DCO2 was used as a measure of net photosynthesis (Figure 3) and was significantly affected by the infestation with aphids also infection of $B$. cinerea affected the rate of photosynthesis significant. The combined effect of Myzus persicae, and $B$. cinerea significantly reduced the rate of photosynthesis (Table 1).

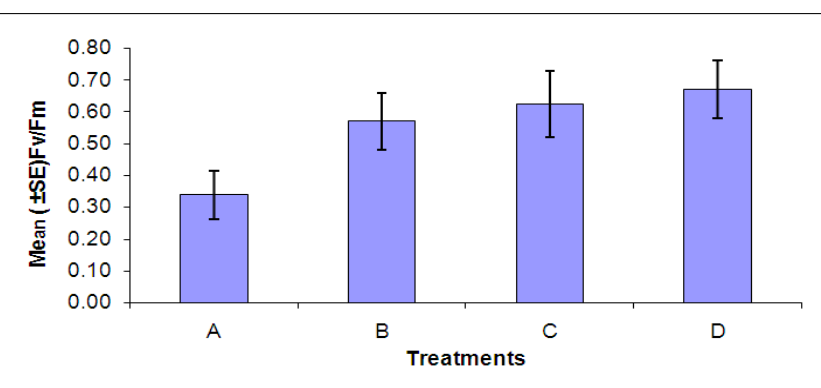

Figure 3: Rate of photosynthesis of plants in each treatment, $(A=$ Infected plant/infested with aphids. B =uninfected plant/infested with aphids. C= Infected plant/uninfested with aphids.

$\mathrm{D}=$ uninfected plant/uninfested with aphids).

Chlorophyll fluorescence: The rate of chlorophyll fluorescence (Fv /Fm) was not significantly affected by M. persicae infestation (Figure 4). Also the effect of $B$. cinerea infection was not significant on the rate of chlorophylly fluorescence. The interaction effect of infection of $B$. cinerea and aphid infestation was not significant. In plants stressed by $M$. persicae infestation (Figure 5), an increase in Fo (minimal chlorophyll fluorescence) was accompanied by a decrease in Fm (maximal chlorophyll fluorescence). An increase in Fo is one of the characteristics indicating inactivation of PSII system while a decline in Fv indicates an increase in a non-photochemical quenching process at or close to the reaction center [41].
Dry mass

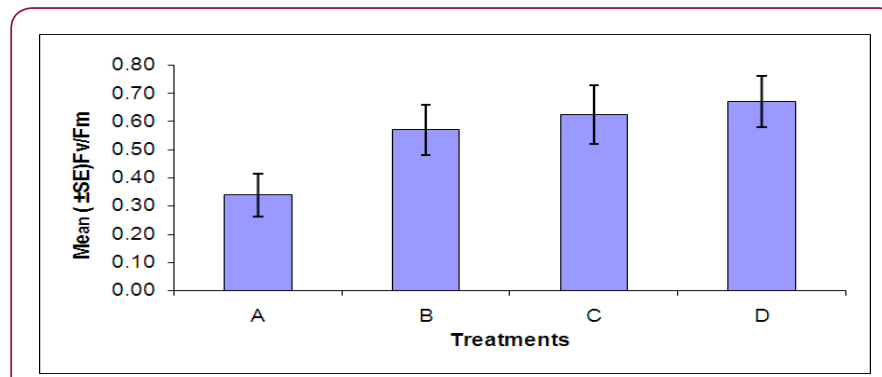

Figure 4: Rate of chlorophyll fluorescence of plants in each treatment. $(A=$ Infected Plant/infested with aphids. $\mathrm{B}=$ uninfected plant/infested with aphids. $\mathrm{C}=$ Infected Plant/uninfested with aphids. D = uninfected plant/ uninfested with aphids). chlorophyll fluorescence of plants in each treatment. $(A=$ Infected Plant/infested with aphids. $\mathrm{B}=$ uninfected plant/infested with aphids. C= Infected Plant/uninfested with aphids. D = uninfected plant/uninfested with aphids).

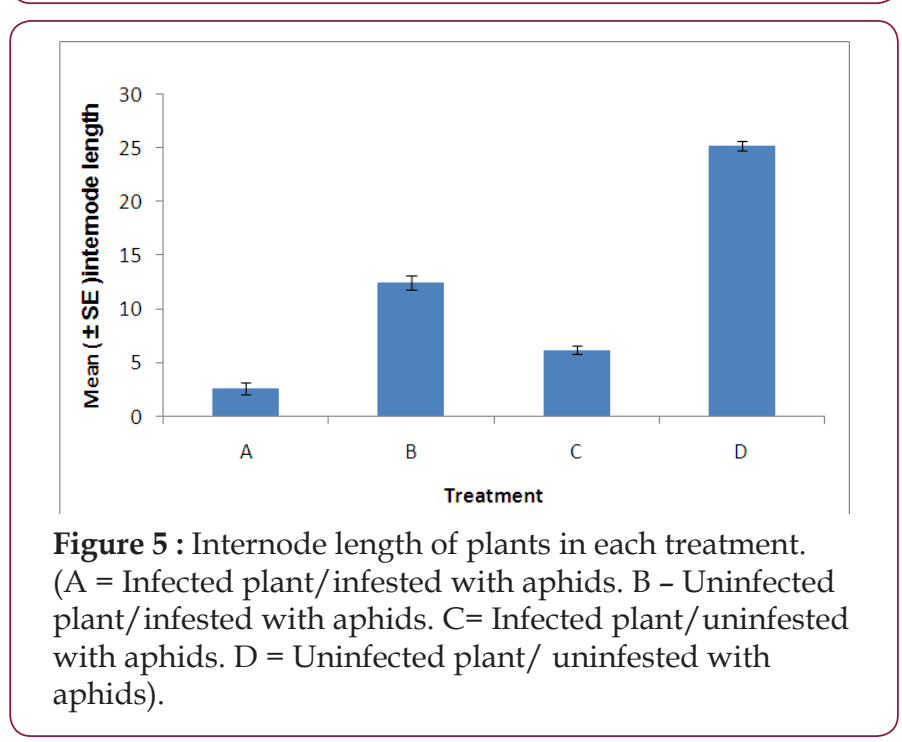


Internode length: There was a significant difference in the internode length between aphid, Myzus persicae, infested and uninfested plants (Figure 5). Also a significant difference was found between plants infected with $B$. cinerea and those which were uninfected. Indicating that infestation with aphids or infection with $B$. cinerea can cause stress on the plant resulting in the decrease in internode length. The combined effects of aphid and B. cinerea also significantly reduces the dry root weight (Figure 5).

Dry shoot weight: There was a significant difference in the dry shoot weight between aphid infested and uninfested plants (Figure 6). A significant difference was found between plants infected with $B$. cinerea and those which were uninfected. This indicates that aphid infestation or infection with $B$. cinerea can cause stress to the plant resulting in a decrease in dry shoot weight. The combined effects of aphid infestation and B. cinerea also significantly reduces the dry shoot weight.

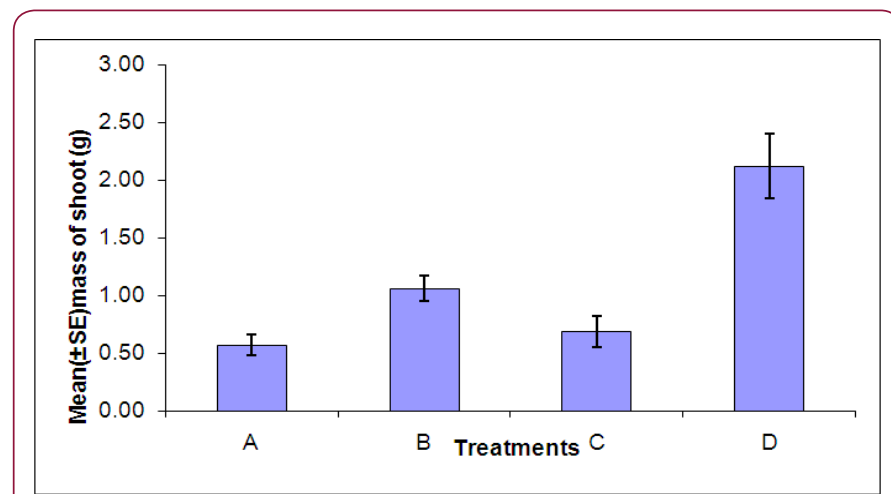

Figure 6 : Dry shoot weight of plants in each treatment. $(\mathrm{A}=$ Infected plant/infested with aphids. $\mathrm{B}=$ uninfected plant/infested with aphids. $C=$ Infected plant/uninfested with aphids. $\mathrm{D}=$ uninfected plant/uninfested with aphids.

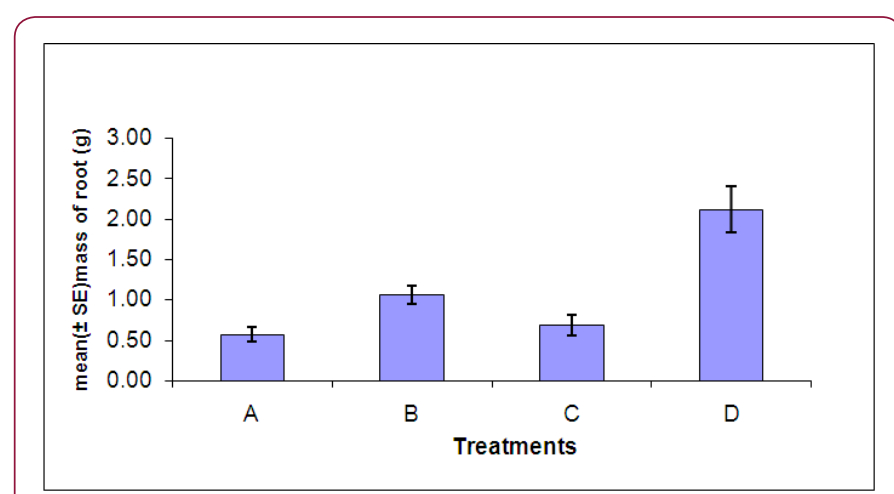

Figure 7 : Dry root weight of plants in each treatment. (A = Infected plant/infested with aphids. B - Uninfected plant/infested with aphids. $C=$ Infected plant/uninfested

with aphids. D = Uninfected plant/ uninfested with aphids).

Dry root weight: There was a significant difference in the dry root weight between aphid, Myzus persicae, infested and uninfested plants (Figure 7). Also a significant difference was found between plants infected with $B$. cinerea and those which were uninfected.
Indicating that infestation with aphids or infection with $B$. cinerea can cause stress on the plant resulting in the decrease of dry root weight. The combined effects of aphid and B. cinerea also significantly reduces the dry root weight.

\section{Discussion}

The results show that lettuce plants infested with three aphids die completely eight weeks after infestation. The rate of population growth of the aphids was slower on infected lettuce plants but very rapid in uninfected plants. Lesions of $B$. cinerea were high in uninfested plants but lower number of $B$. cinerea lesions were recorded in infested lettuce plants. The effects of stress were evident in lettuce plants as the presence of aphids and B. cinerea significantly affected the rate of photosynthesis, and dry mass of the plants. However, the effect of infection by B. cinerea infection and infestation with aphids were not significant on the rate of chlorophyll fluorescence. Among the four lettuce treatments (i) infected/infested (ii) uninfected/infested (iii) infected/uninfested (iv) uninfected/uninfested plants, the highest aphid counts and $B$. cinerea lesion counts were recorded in uninfected/infested plants. The lowest aphid counts and the number of B. cinerea lesions counts were recorded in infected/infested plants.

The present study has confirmed an interaction between two economically important pests of lettuce, the aphid Myzus persicae and the fungal pathogen, Botrytis cinerea. Their interaction results in a reduced rate of population growth of the aphids and lower numbers of B. cinerealesions on the plants. These findings agree with [42] who reported an indirect interaction between phytophagous arthropods and pathogens sharing a host plant. They found that B. cinerea induces the plant host to produce secondary metabolites which cause toxic, antifeedant or aversive effects against aphids, whilst in return aphids (Rhodobium porosum Sanderson) induce the host plant to synthesize salicylic acid, a hypersensitive response around the pathogen site resulting in isolation of the pathogen from the rest of the plant. The interaction results in a decreased growth rate of aphids and also a decrease in B. cinerea lesions, a measure of the pathogens growth rate [42].

Historically, aphid damage has been ascribed to the injection of phytotoxin during feeding, which is responsible for chloroplast disintegration [43]. However, the exact mechanism by which aphids affect plant metabolism is not fully understood, but studies [44-46] show that the induction of defence is costly; resulting in an increased need for assimilates by the plant. In addition, the herbivore attempts to manipulate the plant's carbohydrate metabolism of the plant for its own use [47] As demonstrated in our study, [48] reported a decrease of the chlorophyll content of leaves infected by B. cinerea and infested with aphids, due to an increase in the production of defensive compounds. However, contrary to our findings, the work published by [49] on resistant cereals and studies on wheat by Franzel et al [50] reported that infestation of the plants with aphids had no significant effects on the rate of chlorophyll fluorescence. However, Rafi et al. (1996) concluded that the response of plants to insect herbivore attack differ from species to species. 
The present study established that both dry weight of root and shoot and internode length were significantly reduced by both $M$. persicae and B. cinerea attack. Reduction of the root dry weight in plants infested with aphids was found to be associated with the continuous removal of the assimilate which would have otherwise been stored by the root. Also continual respiration by the plant in response to wounding and/or salivation by the aphid contributed to the reduction of the plant dry weight $[51,52]$ Stress, resulting from aphid infestation, inhibits the electron transport system in photosystem II, causing a decrease in the rate of photosynthesis IIik et al. [53] concluded that the reduction in the rate of photosynthesis in leaves which have been injured by aphid infestation and pathogen attack occur due to the increased synthesis of defensive chemicals in response to the herbivores.

It was clear that the effects of aphid infestation are detrimental to the expression of B. cinerea in lettuce plants and it is suggested that the reaction shown by lettuce plants due to aphid infestation was more than the response shown due to pathogen attack. The systemic B. cinerea alters the condition of the plant host in a way that results in it becoming unfavourable for the second attacker, by inducing the plant to synthesize secondary metabolites which have either toxic effects, aversive and/or anti feedant effects on the aphids $[54,55]$. Such a negative relationship causes a reduction in the reproduction rate of Myzus persicae there by lowering its population size. This indicates a potential role of indirect interactions in changing the ecological interactions and spatial distribution of the insect herbivore [56-59].

The result of the present study indicated that Myzus persicae infested plants show reduced expression of B. cinerea lesion as compared to the non- infested plants. Similarly, Mouttet et al. (2011) reported infestation with aphids (Rhodobium porosum Sanderson) results in the low expression of $B$. cinerea in rose plants, and the infestation triggers the plants to induce the cascade of reactions in the salicylic acid (SA)-dependent pathway. In addition continuous feeding on cell contents by the aphids causes the plant to induce the wound-response pathways, (jasmonic acid (JA)/ethylene (ET) dependent pathways) which reduce the population of aphids [6063].

This research has provided useful insights into the indirect interaction between a systemic pathogen and an insect herbivore in lettuce plants. The results show the existence of a bi-directional relationship between $M$. persicae and B. cinerea where they both stress the host plant, and reduces the population growth rate of each other, probably by triggering the induction of chemicals by the plant. This shows that the pathogenic fungi clearly have farreaching effects on the coexisting insect herbivores.

\section{Acknowledgement}

We thank to Amanda Livermore for providing the original Myzus persicae used in the experiment, in addition providing helpful information on aphid rearing.

\section{References}

1. Polumbo JC (2001) Influence of Admire and Platinum on the population growth of the lettuce aphid under field conditions pp. 14-19.
2. Sowley E NK (2006) Epidemiology of Botrytis cinerea. PhD Thesis School of Biological Science University of Reading, Winter diseases of lettuce, US.

3. Rennie WD (2009) Insects and Diseases: A Popular Account of the Way in Which Insects may Spread or Cause some of our Common Diseases p. 55.

4. James WC (1974) Assessment of plant diseases and losses. Annual review of phytopathology 12: 12-48.

5. Arnold AE, Maynard Z, Gilbert GS, Coley PD, Kursar TA (2000) Are Tropical fungal endophytes hyperdiverse? Ecology letters 3: 267-274.

6. Droby S, Lichter A (2004) Post -harvest Botrytis infection: Etiology, Development and management. Botrytis: Biology, pathology and Control pp. 349-367.

7. Tejesvi MV, kini KR, Prakash HS, Shetty HS (2007) Genetics diversity and antifungal activity of species of pestalotiopsis isolated as endophytes from medicinal plants. Fungal Diversity 24: 37-54.

8. Williamson B, Tudzsnki B, Tudzynski P, Van Kan JAL (2007) Botrytis cinerea: the cause of grey mould disease. Molecular plant pathology 8(5): 561-580.

9. Elad Y, Williamson B, Tudzynski P, Delen N (2004) Botrytis spp. and diseases They cause in agricultural systems. In: Y. Elad (Ed.), Botrytis, Biology Pathology and Control. Kluwer Academic Publishers, Dordrecht p 1-8.

10. Samir D, Amnon L (2007) Post -harvest Botrytis infection: Etiology, development and Management. Botrytis: Biology Pathology and Control. Springer Dordrecht, The Neatherland, pp. 449-367.

11. Zhao M, Zhao J, Wei Wei S, You Jiu T (2009) Boty-II, a novel LTR retrotransposon in Botrytis cinerea B05. 10 revealed by genomic sequence. Electronic Journal of Biotechnology 12(3).

12. Holz G, Coertze S, Williamson B (2004) The ecology of Botrytis on plant surface. In Y. Elad (eds). Botrytis, Biology Pathology and Control. Kluwer Academic publishers, Publishers, Dordrecht p. 9-24.

13. Van Kan JAL (2005) Infection strategies of Botrytis cinerea. Acta Horticulture 669: 77-89.

14. Elad Y, Zimand G, Zaqs Y, Zuriel S, Chet I (2007) Use of Trichoderma. harzianum in combination or alteration with fungicides to control cucumber grey. mould (Botrytis cinerea) under commercial conditions. Plant pathology 42: 324-332.

15. Elias NKS, Fiona MW, Shaw MW (2010) Persistent symptomless, systemic, and Seed-borne infection of lettuce by Botrytis cinerea. European Journal of plant pathology 126: 61-71.

16. Ramu S, Kuppusamy P, Lingan R, Gandhi K (2011) Efficacy of different biological control agents against major postharvest pathogens of grapes under room temperature storage condition. Phytopathology 50: 55-65.

17. Nikolaos EM, Dimitris EG (2002) Fungal and Bacterial diseases. In R. Albajes (eds) Integrated pest and diseases management in greenhouse crop. Kluwer Academic Publishers. New York, Boston, Dordrecht, London, Moscow. p. 34-46.

18. Blackman RL, Eastop VF (2007) Aphids as crop pest. Cabs

19. Takada H (1979) Characteristics of forms of Myzus persicae (Sulzer) (Homoptera:Aphididae) distinguished by color and esterase differences and their occurrence in populations on different host plants in Japan. Applied Entomology and Zoology 14: 370-374.

20. Weber G (1985) Genetic variabity of host plant adaptation of the green peach aphid, Myzus persicae. Entomologiaa Exparimentalis et Applicata 38: 49-56.

21. Polgar LA, Darvas WV, Porcheran P, Szekacs A, Szelinger S, et al. (1996) Comparism of Ecdysteroid concentration in different morphs of aphids. Comparative Biochemistry and Physiology 115: 179- 186.

22. Eisen J (2010) Genome Sequencing of the Pea Aphids Acrythosiphon pisum. The Aphid Genome Consortium. Plos Biology 8(2).

23. Blackman R L, Eastop VF (2000) Aphids on the worlds herbaceous plants and shrubs, UK. 
24. Fellowes MDE, Van Alphen JJM, Jervis M (2005) Insects as Natural Enemies: A Practical Perspective pp. 1-77.

25. Eastop VF (1972) Deductions from present day host plants of aphids and related insects. In insect /plant relationships 6: 157-178.

26. Stacey DA, Thomas MB, Blanford S, Pell JK, Pugh C, Fellowes MDE (2003) Genotype and temperature influence pea aphid resistance to a fungal entomopathogen. Physiological Entomology 28: 75-81.

27. Dixon AFG (1998) Aphid Ecology: An optimization approach.

28. Ryder EJ (1999) Lettuce, endive and chicory CAB International.

29. Polumbo JC, Mullis jr, Reyes F, Amaya A (1998) New Insecticide Alternatives for aphid Management in head lettuce. In N. F. Oebker (eds), Vegetable report series p.115.

30. Kluth S, Kruess A, Tscharntke T (2001) Interactions between the rust fungus Puccinia Punctiformis and ectophagous and endophagous insects on creeping. Journal of Applied Ecology 38: 548-556.

31. Hatcher PE, Paul ND, Ayres P D, Whittaker J B (1995) Interactions between Rumex spp. Herbivores and rust fungus: the effect of Uromyces infection on leaf nutrition quality. Functional Ecology 9: 97-105.

32. Stout MJ, Thaler JS, Thomma BP (2006) Plant-Mediated Interactions between pathogenic microorganisms and herbivorous arthropods. Annual review of Entomology 51: 663-89.

33. Barbosa P (1991) Plant pathogens and non-vector herbivores. In: Barbosa, P. Krischik, VA, Jones,

CG (eds) Microbial mediation of plant-herbivore interactions. USA, pp. 341382.

34. Krues A (2002) Indirect interaction between a fungal plant pathogen and a herbivorous beetle of

the weed Cirsium arvense. Oecologia 130: 563-569.

35. Rodger G, Rahier M, Naisbit RE (2007) Coping with an antagonist: the impact of a Phytopathogenic fungus on the development and behaviour of two alpine leaf beetle. Oikos 116: 1514-523.

36. Cory JS, Hoover K (2006) Plant- mediated effects in insect-pathogen interactions. Trend in Ecology and Evolution 21(5): 169-174.

37. Rajaguru BAP (2008) Molecular ecology of Botrytis cinerea. PhD Thesis School of Biological

Sciences, University of Reading.

38. Shafia A (2009) Latent infection of Botrytis cinerea. PhD Thesis School of Biological Sciences, University of Reading.

39. Suarez MB, Walsh K, Booham N, O'Neil T, Pearson S, Baker I (2005) Development of freal time (Taqman) assay for the detection and quantification of B. cinerea. Plant physiology and Biochemistry 43(9): 890-899.

40. Zlatko SZ, Yordanov IT (2004) Effects of soil drought on photosynthesis and chlorophyll fluorescence in bean plant . Bulgarian Journal of plant pathology 30: 3-18.

41. Mouttet R, Philippe, Cecile T, Nicolas D (2011) Phytophagous arthropods and pathogen sharing host plant: Evidence for indirect plant-mediated interactions. Plos One 6:188.

42. Anna MB, Leon V, Carlo SJ, Francois N, Burger V, et al. (2012) Phloem feeding Insect Stress and Photosynthetic Gene Expression, M. Najafpour (eds) Applied Photosynthesis, phloem-feeding-insect-stress andphotosynthetic-gene- Expression.

43. Heil M, Bostock RM (2002) Induced systemic resistance (ISR) against pathogens in the context of induced plant defences. Annual of Botany 89: 503-512.

44. Swarbrick PJ, Schulze-Lefert, P, Scholes D (2006) Metabolic consequences of susceptibility and resistance in barley leaves challenged with powdery mildew. Plant cell and environment 29(6): 1061-1076.
45. Golawska S, Krzyzanowski R, Łukasik I (2010) Relationship between aphid infestation and chlorophyll content in Fabaceae species. ACTA Biologica Cracoviesia series Botanica 52: 76-80.

46. Rodriguez-Saona C, Law BR, Rufus I (2011) Manipulation of natural enemies in Agroecosystems: Habitat and semiochemicals for sustainable insect pest control-current and future tactics pp. 96-125.

47. Karavaev V, Polyakova I (2000) Slow fluorescence induction and photosynthesis in bean and cabbage leaves infected by Botrytis cinerea XIIth International Botrytis Symposium,France.

48. Rafi MM, Zemetra RS, Quisenberry SS (1996) Interaction between Russian wheat aphid (Homoptera: Aphididae) and resistant and susceptible Genotype of wheat. Journal of Economic Entomology 89: 239-246.

49. Franzen L D, Andrea R, Tiffany M, Heng-Moss L, Higley G, et al. (2007) Physiological and Biochemical Responses of Resistant and Susceptible Wheat to Injury by Russian Wheat Aphid. Journal of Economic. Entomology.100(5): 1692 -1703.

50. Mackauer M, Way MJ (1976) Myzus persicae Sulz an aphid of world importance. In V. L. Delucchi (eds). Studies in Biological Control. International Biological programme 9, Cambridge University press.

51. Shannag HK, Ababneh JA (2007) Biometry and response of faba bean varieties to black bean aphid, aphis fabae Scopoli. Journal of Agric and environmental Science 2: 328-334.

52. Heng-Moss TM, Macedo T, Markwell JP, Baxebdale FP, Quisenberry S, et al. (2003) Comparison of chlorophyll and carotenoid concentrations among Russian wheat aphid (Homoptera: Aphididae)-infested. wheat isolines. Plant Resistance 96(2): 475-481.

53. Biere A, Mark HB, Van Damme JMM (2004) Plant chemical defence against herbivores and pathogens: generalised defence or trade-offs? Oecologia 140(3): 430-441.

54. Walling LL (2000) The myriad plant responses to herbivores. Journal of plant growth regulation 19(2): 195-216.

55. Paul ND, Hatcher PE, Taylor JE (2000) Coping with multiple enemies: an integration of molecular and ecological perspectives. Trends in plant science 5(5): 220-225.

56. Ohgushi T (2005) Indirect interaction webs: Herbivore-induced effects through trait change in plant. Journal of Annual Review of Ecological System 36: 81-105.

57. Viswanathan DV, McNickle G, Thaler J S (2008) Heterogeneity of plant phenotypes caused by herbivore-specific induced responses influence the spacial distribution of herbivores. Ecological Entomology 33: 86-94.

58. Kerry E M, Consuelo M D, Mark CM (2010) Effects of cucumber mosaic virus infection on vector and non-vector herbivores of squash. Communicative and integrative Biology 3(6): 579-582.

59. Kanno H, FujitaY (2003) Induced systemic resistance to rice blast fungus in rice plants.

60. De vos M Van, Zaanen W, Koorneef A, Korzelius J P, Dicke M (2006) Herbivore -Induced resistance against microbial pathogens in Arabidopsis. Plant Physiology 142(1): 352-363.

61. Infested by white-backed plant-hopper. Entomology Experiment and Applied 107: 155-158

62. Hatano E, Kunert G, Michaud JP, Weisser W (2008) Chemical cues mediating aphid aphid location by natural enemies. European journal of Entomology 105: 797-806.

63. Wassim EC, Roy K, Tatyana S, Heather R, Florence N, et al. (2008) Distinct Roles of Jasmonates and Aldehydes in Plant-Defense Responses PloS ONE 3(4): e1904. 


\begin{tabular}{ll}
\hline $\begin{array}{l}\text { BIOMEDICAL } \\
\text { RESEARCHES }\end{array}$ & Assets of Publishing with us \\
& - Global archiving of articles \\
\hline & - Immediate, unrestricted online access \\
\hline
\end{tabular}

